\title{
Advanced Microscopic Study of Suspension Plasma-Sprayed Zirconia Coatings with Different Microstructures
}

\author{
Paweł Sokołowski, Lech Pawłowski, Dagmar Dietrich, Thomas Lampke, and David Jech
}

(Submitted June 10, 2015; in revised form August 8, 2015)

\begin{abstract}
The present paper is focused on the characterization of the differences between two microstructures that can be obtained using SPS technology, namely (i) columnar and (ii) two-zone microstructure including lamellas and fine unmelted particulates. The optimization of spray parameters was made, and the advanced microstructural studies of obtained coatings were performed. The work was focused on zirconia stabilized by yttria (YSZ, $\mathrm{ZrO}_{2}+14$ wt. $\left.\% \mathbf{Y}_{2} \mathrm{O}_{3}\right)$ and both by yttria and ceria (YCSZ, $\mathrm{ZrO}_{2}+24$ wt. $\%$ $\mathrm{CeO}_{2}+2.5$ wt. $\% \mathrm{Y}_{2} \mathrm{O}_{3}$ ) which are frequently used as thermal barrier coatings. Two types of microstructure were achieved using two different plasma torches, namely SG-100 of Praxair and Triplex of Oerlikon Metco. The microstructure of prepared coatings was analyzed using scanning electron microscopy with secondary electrons detector and backscattered electrons. Energy dispersive spectroscopy was performed to analyze the chemical composition of sprayed coatings. By electron backscatter diffraction grain shape, size, and crystal orientation were determined. The analysis enabled the discussion of the coatings growth mechanism. Finally, the Shape From Shading technique was applied to recreate and to analyze 3D views of coatings' topographies, and using laser confocal microscopy, the surface roughness was examined.
\end{abstract}

Keywords columnar microstructure, electron backscatter diffraction, suspension plasma spraying, thermal barrier coatings, two-zone microstructure, yttriaceria-stabilized zirconia, yttria-stabilized zirconia

\section{Introduction}

Suspension plasma spraying (SPS) is a modification of the atmospheric plasma spraying (APS) processes. The complexity of SPS results from the necessity of controlling the phenomena related to the use of liquid feedstock instead of powder (Ref 1,2). Thanks to the use of suspension, the submicrometric or nanometric size solids can be introduced in the plasma jet. The resulting coatings are very finely grained (Ref 3,4$)$. The window of optimal SPS process parameters is narrow. The changes in spray conditions result in different coatings' morphologies.

This article is an invited paper selected from presentations at the 2015 International Thermal Spray Conference, held May 11-14, 2015, in Long Beach, California, USA, and has been expanded from the original presentation.

Paweł Sokołowski, Wrocław University of Technology, Wrocław, Poland and University of Limoges, Limoges, France; Lech Pawłowski, University of Limoges, Limoges, France; Dagmar Dietrich and Thomas Lampke, Chemnitz University of Technology, Chemnitz, Germany; and David Jech, Brno University of Technology, Brno, Czech Republic. Contact e-mail: pawel.sokolowski@pwr.edu.pl.
Kozerski et al. (Ref 5) described the mechanism of formation of two-zone microstructure, which is typical for SPS process. The dense zone, included in the coatings, has well melted and relatively large lamellas, and unmelted particle zone has irregularly distributed, more or less sintered, very fine grains. The formation of two-zones microstructure resulted from the small size of powder particles and from different trajectories of particles in plasma jet which led to the differences in the heat treatment of solids by the heat generated by plasma. But more recently, many researchers analyzed the possibilities of producing columnar-like microstructure using SPS technology. VanEvery et al. (Ref 6) proved that using axial injection of precursor, the columnar microstructure can be produced. The same effect was achieved by Sokołowski et al. (Ref 7) for radially injected suspensions by changing the amount of the solid phase in the suspension and/or by appropriate preparation of the substrate surface morphology. The columnar structure formation was explained by the deviation of hot stream near the substrate material and sticking of the particles to the peaks of the substrate asperities. In the studied cases, the columnar microstructure occurred only in the coatings sprayed using suspension containing very fine particles.

The columnar microstructure is useful for thermal barrier coatings since it may improve the thermomechanical properties. The main benefit of this type of microstructure is reduction of the residual stresses in the produced coating, higher durability, and resistance for thermal shocks, which influence the increase of the TBC lifetime (Ref 8,9). On the other hand, the fine-grained lamellar microstructure containing a great number of 
regularly distributed submicrometer and nanometer sized pores can significantly decrease heat transfer across coatings by decreasing their thermal conductivity (Ref 10,11).

The present study focuses on the microscopic analysis of ceramic topcoats of TBC's having different microstructures. The main objective of the conducted research is to contribute to a better understanding the way of processing and choosing the appropriate process parameters in order to obtain different coating microstructures.

\section{Experimental Procedure}

\subsection{Feedstock Preparation}

The suspensions used in the spray process were prepared using two zirconia powders having different (i) chemical composition and (ii) particle size. The YSZ powder was manufactured by Tosoh (Kyoto, Japan) and had a composition of $\mathrm{ZrO}_{2}+14$ wt. $\% \mathrm{Y}_{2} \mathrm{O}_{3}$. The granulometry tests (DLS method, Zetasizer Nano-ZS, Malvern Instruments) showed that the volume diameter was $d_{\mathrm{v} 10}=137 \mathrm{~nm} ; d_{\mathrm{v} 50}=398 \mathrm{~nm} ;$ and $d_{\mathrm{v} 90}=974 \mathrm{~nm}$, respectively. The powder was used as manufactured (Fig. 1). The second powder, noted as YCSZ, had the trade name Metco205NS and a composition of $\mathrm{ZrO}_{2}+24$ wt. $\% \mathrm{CeO}_{2}$ +2.5 wt. $\% \mathrm{Y}_{2} \mathrm{O}_{3}$ (YCSZ). The initial size of the YCSZ powder was $d_{\mathrm{v} 10}=9.9 \mu \mathrm{m} ; d_{\mathrm{v} 50}=39.6 \mu \mathrm{m}$; and $d_{\mathrm{v} 90}=66.5$ $\mu \mathrm{m}$. The powder was crushed mechanically using ball milling (moliNEx system, NETZSCH). The mechanical treatment allowed decreasing of powder's particle size (Fig. 2). The granulometry tests (DLS method, Partica LA-950V2, Horiba) showed that the volume diameter was equal to $d_{\mathrm{v} 10}=483 \mathrm{~nm} ; d_{\mathrm{v} 50}=696 \mathrm{~nm}$; and $d_{\mathrm{v} 90}=4.7 \mu \mathrm{m}$.

Then the suspensions including YSZ and YCSZ were formulated with different fractions of solid phase. The fractions were torch specific: $2.5,5$, and $10 \mathrm{wt}$. $\%$ of powder for SG-100 torch and 5, 10, and $20 \mathrm{wt}$ \% of powder for Triplex torch. The greater concentration of solid resulted from the higher electric power input of the Triplex torch. The liquid phase in suspension included water and ethanol in ratio 1:1 and small quantity of dispersant agent (Beycostat C213, CECA, France). The details of feedstock preparation are shown elsewhere $(\operatorname{Ref} 7,12)$.

\subsection{Spray Experiments}

The zirconia coatings were produced using two spray setups equipped with different plasma torches (SG-100 and Triplex), and the deposition parameters were optimized separately for each torch (Ref 7). Moreover, the influence of the substrate topography on the coatings' microstructure was tested. The topographies were generated with (i) grit blasting; (ii) grinding; (iii) turning; and (iv) laser treatment. All substrates were cleaned ultrasonically in the in ethanol bath prior to spraying.

Finally, it can be concluded that four process variables were chosen in the spray experiments: (i) type of powder; (ii) concentration of solid phase in suspension; (iii) sub-

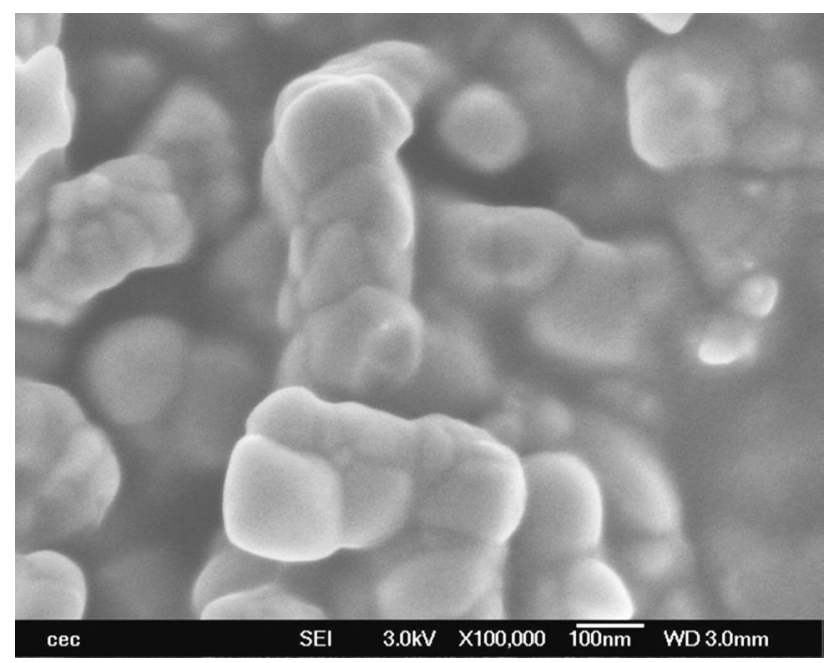

Fig. 1 SEM morphology (secondary electrons) of YSZ powder

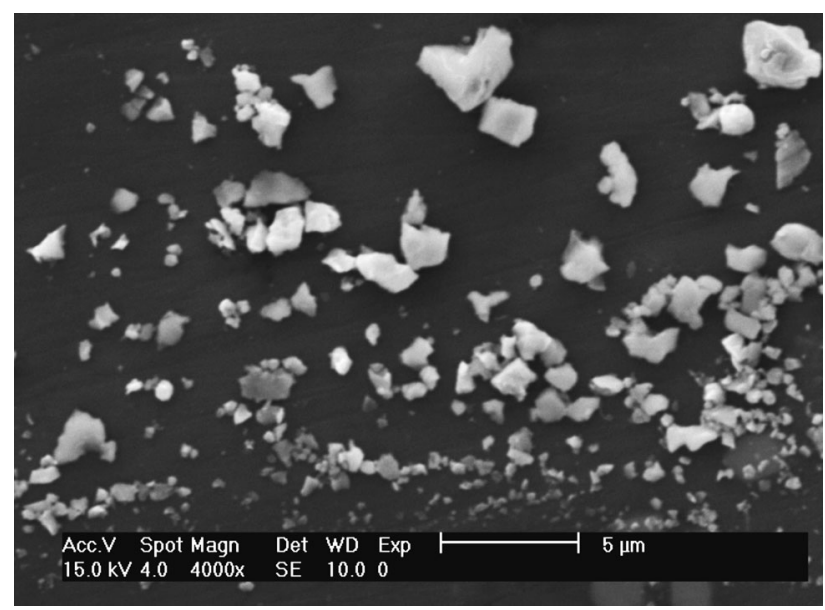

Fig. 2 SEM morphology (secondary electrons) of YCSZ powder particles after milling

strate topography; and (iv) torch type. As a result, 12 spray runs were performed for each torch type and, taking into account 4 types of substrates preparation, 36 different coatings were obtained for further analyses (Table 1).

\subsection{Microstructure Characterization}

The microscopic studies required very careful metallographic preparation of specimens. The mounting of samples was carried out using the electrically conducting bakelite resin with carbon filler (Polyfast Struers). The samples were then ground and polished-also with the final polishing with colloidal silica oxides (OPS Struers). The samples were cleaned in ethanol, dried, and coated with a very thin carbon layer.

The observations were carried out using two different microscopes: (i) Leo 1455VP (Carl Zeiss GmbH) with Metek EDS detector of EDAX was used for SEM observations and EDS measurements; (ii) Neon 40ESB 


\begin{tabular}{|c|c|c|c|c|c|c|c|c|c|}
\hline Run & Powder material & $\begin{array}{c}\text { Concentration } \\
\text { of powder in the } \\
\text { suspension, \% }\end{array}$ & Plasma torch & Substrate preparation & Sample & $R_{\mathrm{a}}, \mu \mathrm{m}$ & St. dev., $\mu \mathrm{m}$ & $R_{\mathrm{z}}, \mu \mathrm{m}$ & St. dev., $\mu \mathrm{m}$ \\
\hline \multirow[t]{3}{*}{1} & YSZ-Tosoh & 2.5 & SG-100 & GB & ST21 & 10.7 & 1.6 & 57.4 & 14.2 \\
\hline & YSZ-Tosoh & 2.5 & SG-100 & LT & ST22 & 8.2 & 0.4 & 50.9 & 4.0 \\
\hline & YSZ-Tosoh & 2.5 & SG-100 & $\mathbf{G}$ & ST23 & 7.9 & 1.5 & 51.2 & 8.9 \\
\hline \multirow[t]{3}{*}{2} & YSZ-Tosoh & 5 & SG-100 & GB & ST51 & 10.6 & 1.2 & 58.2 & 7.5 \\
\hline & YSZ-Tosoh & 5 & SG-100 & $\mathbf{L T}$ & ST52 & 7.4 & 0.9 & 43.5 & 4.1 \\
\hline & YSZ-Tosoh & 5 & SG-100 & $\mathrm{G}$ & ST53 & 5.7 & 0.4 & 33.5 & 2.1 \\
\hline \multirow[t]{3}{*}{3} & YSZ-Tosoh & 10 & SG-100 & GB & ST101 & 7.2 & 0.7 & 40.9 & 5.3 \\
\hline & YSZ-Tosoh & 10 & SG-100 & $\mathbf{L T}$ & ST102 & 5.9 & 0.6 & 39.0 & 4.1 \\
\hline & YSZ-Tosoh & 10 & SG-100 & G & ST103 & 3.9 & 0.7 & 24.8 & 3.8 \\
\hline \multirow[t]{3}{*}{4} & YCSZ & 2.5 & SG-100 & GB & SC21 & 8.3 & 0.8 & 49.4 & 5.0 \\
\hline & YCSZ & 2.5 & SG-100 & $\mathrm{T}$ & SC22 & 4.0 & 0.4 & 32.7 & 4.7 \\
\hline & YCSZ & 2.5 & SG-100 & G & SC23 & 5.5 & 0.7 & 35.0 & 5.5 \\
\hline \multirow[t]{3}{*}{5} & YCSZ & 5 & SG-100 & GB & SC51 & 6.8 & 0.7 & 39.4 & 5.6 \\
\hline & YCSZ & 5 & SG-100 & $\mathrm{T}$ & SC52 & 3.7 & 0.6 & 28.5 & 7.8 \\
\hline & YCSZ & 5 & SG-100 & G & SC53 & 4.2 & 0.7 & 29.5 & 7.0 \\
\hline \multirow[t]{3}{*}{6} & YCSZ & 10 & SG-100 & GB & SC101 & 6.7 & 0.7 & 38.0 & 3.1 \\
\hline & YCSZ & 10 & SG-100 & LT & SC102 & 3.6 & 0.6 & 26.0 & 3.9 \\
\hline & YCSZ & 10 & SG-100 & $\mathrm{G}$ & SC103 & 4.2 & 0.5 & 27.7 & 3.6 \\
\hline \multirow[t]{3}{*}{7} & YSZ-Tosoh & 5 & Triplex & GB & TT51 & 6.9 & 1.1 & 42.5 & 9.1 \\
\hline & YSZ-Tosoh & 5 & Triplex & LT & TT52 & 6.0 & 0.6 & 38.8 & 6.5 \\
\hline & YSZ-Tosoh & 5 & Triplex & G & TT53 & 2.9 & 0.4 & 20.6 & 2.6 \\
\hline \multirow[t]{3}{*}{8} & YSZ-Tosoh & 10 & Triplex & GB & TT101 & 6.1 & 0.8 & 35.6 & 3.6 \\
\hline & YSZ-Tosoh & 10 & Triplex & $\mathbf{L T}$ & TT102 & 6.5 & 1.3 & 38.3 & 8.1 \\
\hline & YSZ-Tosoh & 10 & Triplex & G & TT103 & 2.3 & 0.3 & 19.3 & 3.3 \\
\hline \multirow[t]{3}{*}{9} & YSZ-Tosoh & 20 & Triplex & GB & TT201 & 5.1 & 1.0 & 31.4 & 5.6 \\
\hline & YSZ-Tosoh & 20 & Triplex & LT & TT202 & 3.5 & 0.8 & 23.2 & 5.0 \\
\hline & YSZ-Tosoh & 20 & Triplex & G & TT203 & 2.2 & 0.3 & 18.9 & 3.1 \\
\hline \multirow[t]{3}{*}{10} & YCSZ & 5 & Triplex & GB & TC51 & 3.8 & 0.6 & 25.0 & 1.9 \\
\hline & YCSZ & 5 & Triplex & $\mathrm{T}$ & TC52 & 2.5 & 0.4 & 20.5 & 3.1 \\
\hline & YCSZ & 5 & Triplex & G & TC53 & 2.1 & 0.2 & 14.2 & 1.3 \\
\hline \multirow[t]{3}{*}{11} & YCSZ & 10 & Triplex & GB & TC101 & 3.5 & 0.5 & 24.4 & 3.1 \\
\hline & YCSZ & 10 & Triplex & $\mathrm{T}$ & TC102 & 3.2 & 0.4 & 23.2 & 2.4 \\
\hline & YCSZ & 10 & Triplex & G & TC103 & 2.9 & 0.3 & 22.5 & 3.1 \\
\hline \multirow[t]{3}{*}{12} & YCSZ & 20 & Triplex & GB & TC201 & 3.5 & 0.7 & 25.2 & 5.9 \\
\hline & YCSZ & 20 & Triplex & $\mathrm{T}$ & TC202 & 2.4 & 0.1 & 19.1 & 1.8 \\
\hline & YCSZ & 20 & Triplex & G & TC203 & 2.7 & 0.4 & 20.9 & 2.9 \\
\hline
\end{tabular}

GB — grid-blasting; substrate roughness $R_{\mathrm{a}}=5.5 \mu \mathrm{m}$ and $R_{\mathrm{z}}=32.4 \mu \mathrm{m} ; \mathrm{G}$ - grinding; $R_{\mathrm{a}}=0.1 \mu \mathrm{m}$ and $R_{\mathrm{z}}=0.6 \mu \mathrm{m} ; \mathrm{LT}-$ laser treatment; $R_{\mathrm{a}}=3.6 \mu \mathrm{m}$ and $R_{\mathrm{z}}=17.6 \mu \mathrm{m}$; T-turning; $R_{\mathrm{a}}=0.5 \mu \mathrm{m}$ and $R_{\mathrm{z}}=3.1 \mu \mathrm{m}$

(Carl Zeiss GmbH) with DigiView EBSD camera was used for SEM and EBSD investigations.

The EBSD examination of the coatings' microstructure was made with the following parameters:

- step size of $100 \mathrm{~nm}$;

- beam voltage of $15 \mathrm{kV}$ with an aperture $60 \mu \mathrm{m}$;

- scan speed of 6-10 points per second.

The obtained data were then analyzed using OIM Analysis 6.1 software. The filtering of the data to minimize the effect of some noises, which are unavoidable for this type of analysis, was made based on two types of filters-confidence index (CI > 0.12) or image quality (IQ).

The coating topography was observed using Shape From Shading (SFS) method (Phenom G2 pro, Eindhoven, The Netherlands). Using four different local 2D images of the sample and well-known shadowing effect (Ref 13), the 3D views of coatings surfaces were built-up. Then the topog- raphy profiles could be observed and analyzed (Fig. 3). Finally, the influence of substrate topography and spray process parameters on the surface roughness of the coatings was investigated. In this case, non-contact laser confocal microscopy method was applied (Olympus, LEXT OLS4000 3D Laser Measuring Microscope, Tokyo, Japan).

\section{Results}

\subsection{EDS Chemical Analysis}

The first part of a larger study done on the samples produced as shown in Table 1 contains a basic microstructure characterization and is presented elsewhere (Ref 7). Consequently, to complete the previous studies, the chemical analysis of coatings using Energy Dispersive Spectroscopy was carried out. 

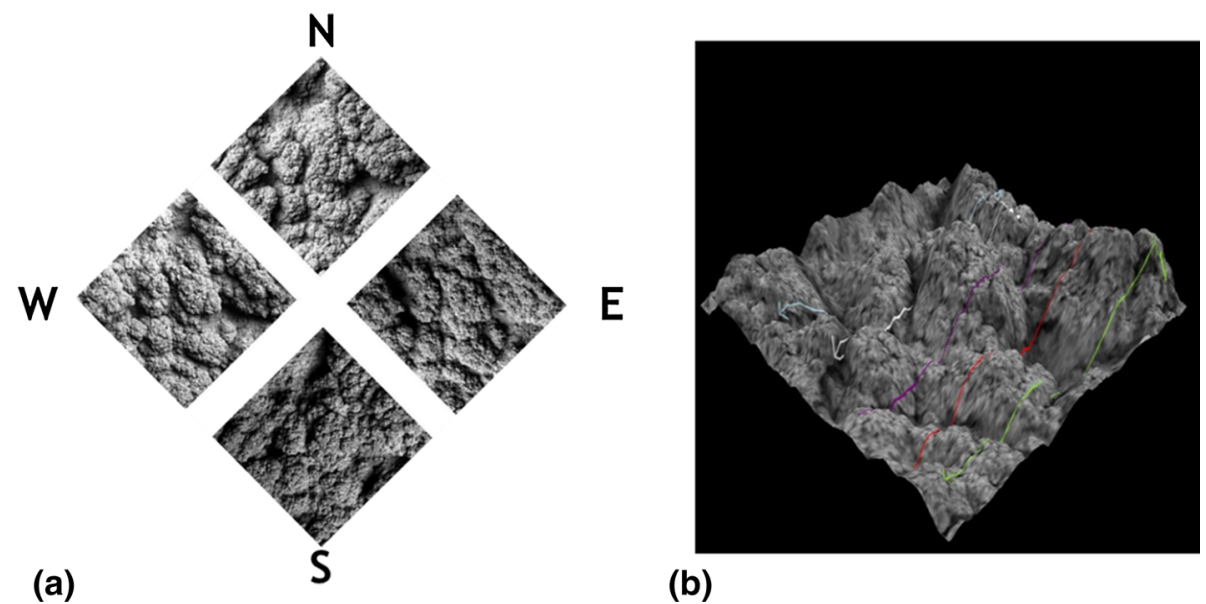

(b)

Fig. 3 Shape From Shading technique: (a) reconstruction of coating surface, (b) 3D view of coating
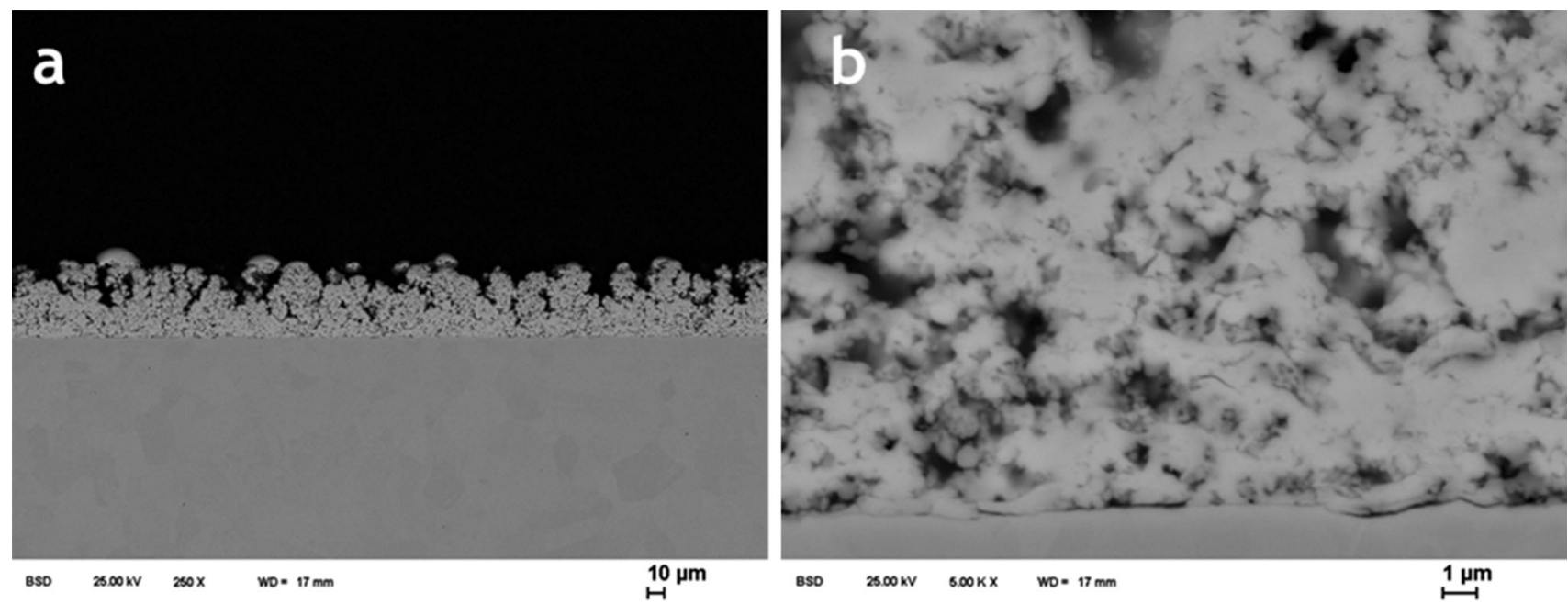

Fig. 4 SEM microstructure (backscattered electrons) of ST23 coatings under magnification of $250 \times($ a) and $5000 \times($ b)

The EDS analysis of the samples sprayed using suspension of YSZ powder showed that the spraying did not introduce significant modification in the chemical composition. The content of the elements in the coating microstructure was as follows: (i) $25-30 \mathrm{wt} \%$ of oxygen, (ii) $14-18$ wt.\% of yttrium; and (iii) $53-58$ wt.\% of zirconium, which corresponds roughly to the initial composition of YSZ-Tosoh powder used to prepare the suspension. The latter was as follows: (i) $25 \mathrm{wt} \%$ of oxygen; (ii) $11 \mathrm{wt} \%$ of yttrium; and (iii) 64 wt. $\%$ of zirconium).

The YCSZ coatings consisted of about (i) 18-23 wt.\% of oxygen; (ii) $15-18$ wt. $\%$ of cerium; (iii) $5-6$ wt. $\%$ of yttrium; and (iv) $56-63 \%$ of zirconium. This composition is quite similar to the initial one which corresponds to (i) 21 wt. $\%$ of oxygen; (ii) $20 \mathrm{wt} . \%$ of cerium; (iii) $2 \mathrm{wt} \%$ of yttrium; and (iv) $47 \%$ of zirconium.

\subsection{Columnar-Like Coatings}

Table 1 shows the process parameters which produced coatings having columnar microstructures. The microstruc- ture was achieved for both plasma setups, different kinds of substrates' surface topographies, and only for fine-grained YSZ powder.

A typical columnar microstructure cross-section is shown in Fig. 4(a) (sample ST23). This sample was particularly interesting because of numerous perpendicular columns having irregular shape, size, and height which were formed onto smooth, ground, substrate surface. The size of pores was nanometric to submicrometric. At assprayed coating/grinded substrate interface, any cracks and any delamination were not observed (Fig. 4b). However, after having cut the sample and having placed it into the conductive resin, some single discontinuities appeared, which were not visible when low-shrinkage resin was used.

The orientation and size of crystal grains in the ST23 coating were investigated using EBSD analysis. The sample had very fine-grained microstructure (Fig. 5). It was possible to observe that finer grains occurred near to the substrate. The top of the coatings included a few, very big, grains which were very different comparing to the rest of the coating microstructure. These grains could have 
been formed by a few droplets of the suspension which leaked out from the injector and fell at the top of a hot sample at the end of the spray process. Three different pole figures $\{001\},\{011\}$, and $\{111\}$ were composed to observe the main crystallite directions. The differences between these orientations were very small and it was not

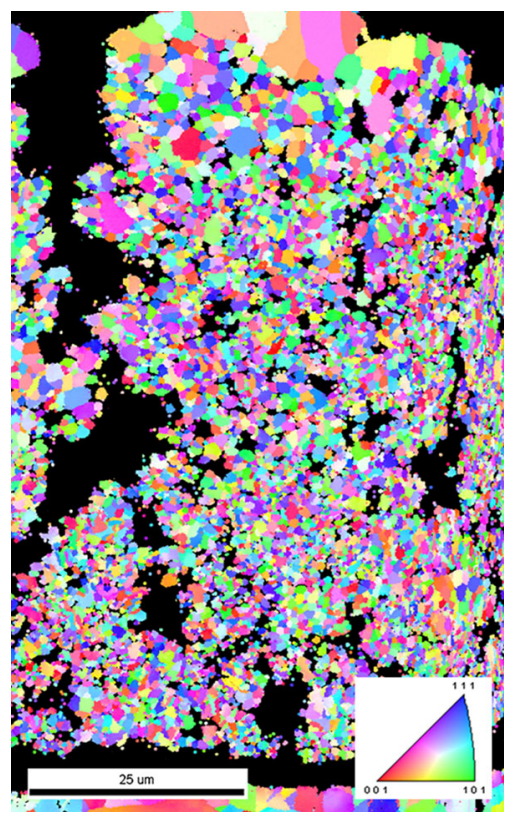

Fig. 5 EBSD image (inverse pole figure) of ST23 sample
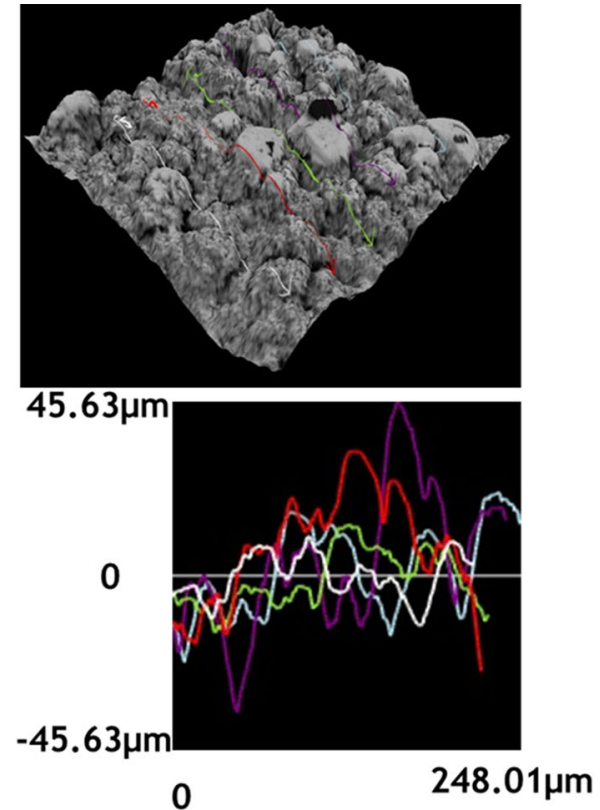

(a) possible to distinguish any preferred directions of columns growth. The main volume grain size was near 600 $\mathrm{nm}$-almost two times bigger than the initial powder particle size. However, the main number grain was of 300 $\mathrm{nm}$ and below, which was close to initial particle powder size.

The coating's surface topography analysis enabled to find out that ST23 coating was the roughest one when taking into account the small initial roughness of substrate surface (Fig. 6a). Consequently, the value of $R_{\mathrm{a}}=7.9 \mu \mathrm{m}$ and $R_{\mathrm{z}}=51.2 \mu \mathrm{m}$ was measured for the coating surface and $R_{\mathrm{a}}=0.1 \mu \mathrm{m}$ and $R_{\mathrm{Z}}=0.6 \mu \mathrm{m}$ for the substrate, respectively.

Another coating having columnar microstructure was ST52 (Fig. 7a). The substrate topography, achieved by laser treatment, influenced the coating morphology. The columnar microstructure was formed in the way that each "peak" corresponded to a column and above the "valleys" the longitudinal pores were formed. The coatings were also denser than sample ST23, because of the use of two times greater suspension concentration. However, a big amount of larger micropores was also observed. Near the top of the coating, the microstructure was very fine grained as observed with the SEM (Fig. 7b).

The EBSD measurement area was chosen in a way that the "peaks and valleys" were analyzed simultaneously (Fig. 8). The measurements showed that the growth mechanism of coating was not the same in the two analyzed regions of the sample. Consequently, the grains, which were deposited above the peaks of the substrate (see no. 2 on Fig. 8a), were rather spherical. On the other hand, the grains solidified between the peaks were more deformed, i.e., thin and perpendicular to the substrate surface (see no. 1 on Fig. 8a). The longitudinal shape of
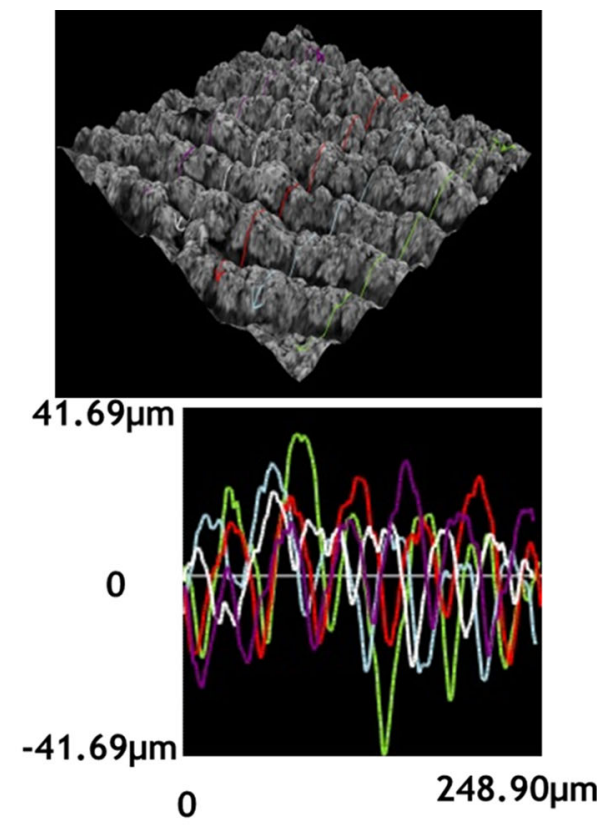

(b)

Fig. 6 Topography of coatings having columnar microstructure (SFS method): irregular, cauliflower-like, surface of ST23 coatings created on grinded surface (a) and very regular coating ST52 created on laser-treated substrate (b) 


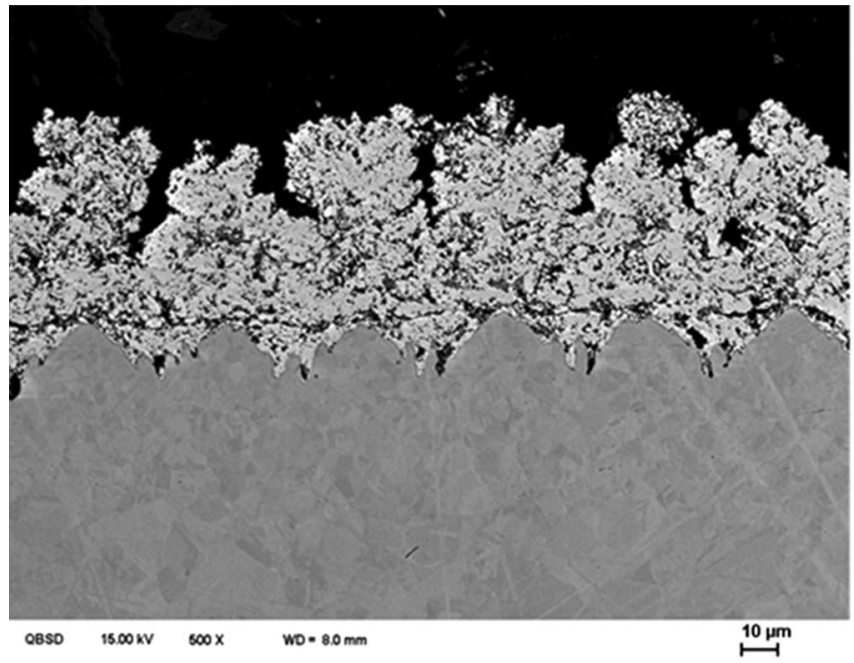

(a)

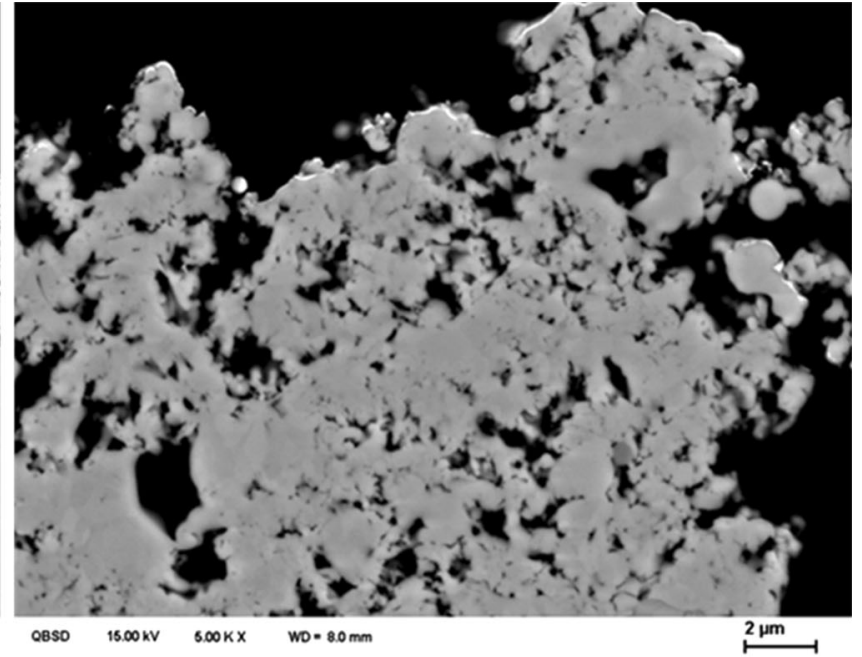

(b)

Fig. 7 SEM microstructure (back scattered electrons) of ST52 coatings with magnification of $500 \times($ a) and $5000 \times(b)$

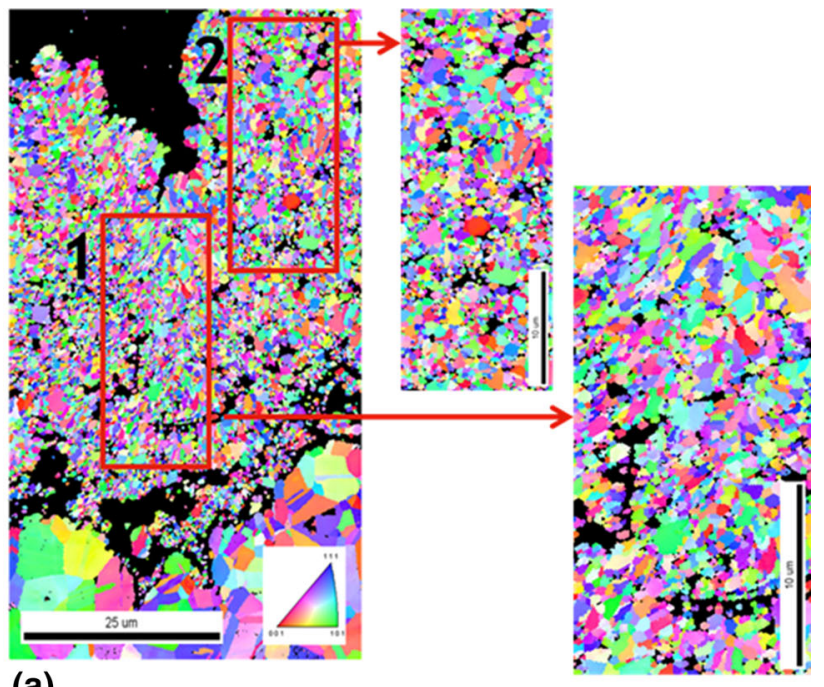

(a)
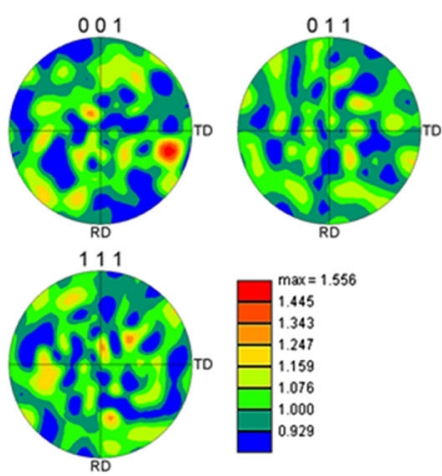

(b)

Fig. 8 EBSD map showing the grains of ST52 coating and their crystallographic orientation (a), and texture analysis performed in area 2 (b) the grains may suggest that coatings have a texture. Because of these differences in the grains morphology, an additional EBSD maps in these two regions of the sample were analyzed (Fig. 8b). But the observed differences between different grain orientations were in fact very small and it was not possible to find any preferred directions of crystal growth. The grain size distribution showed that the grains with the size of about $600 \mathrm{~nm}$ covered the largest area fraction of samples (see Fig. 9a). On the other hand, a great number of small grains with the size of about 250-300 nm were found out (see Fig. 9b). Moreover, the grains which solidified above the peaks of substrate, had slightly smaller size.

SFS enabled to find the cauliflower-like surface morphology in samples with columnar-like structure. The coatings sprayed onto laser-treated substrates had very regular surface. The coating profile was very similar to that of the substrate prior to spraying (Fig. 6b). However, the roughness of coating can be characterized by $R_{\mathrm{a}}=7.4$ $\mu \mathrm{m}$ and $R_{\mathrm{z}}=43.5 \mu \mathrm{m}$, which was still around two times bigger than that measured on the laser-treated substrate prior to spraying $\left(R_{\mathrm{a}}=3.6 \mu \mathrm{m}\right.$ and $\left.R_{\mathrm{z}}=17.6 \mu \mathrm{m}\right)$.

\subsection{Lamellar Coatings}

The lamellar microstructure was observed, i.e., for YCSZ coatings prepared using Triplex torch and suspension having $10 \mathrm{wt} \%$ of solid phase. The microstructure of these coatings was much denser than in columnar-like coatings (Fig. 10a). The presence of cerium could be noticed as bright fields in Fig. 10(b). Finally, it was found that the substrate preparation process did not influence this type of coating microstructure.

The EBSD investigation visualized the thin columns inside the lamellas, especially near the substrate (Fig. 11). The grain size examination, carried out for the TC102

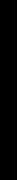




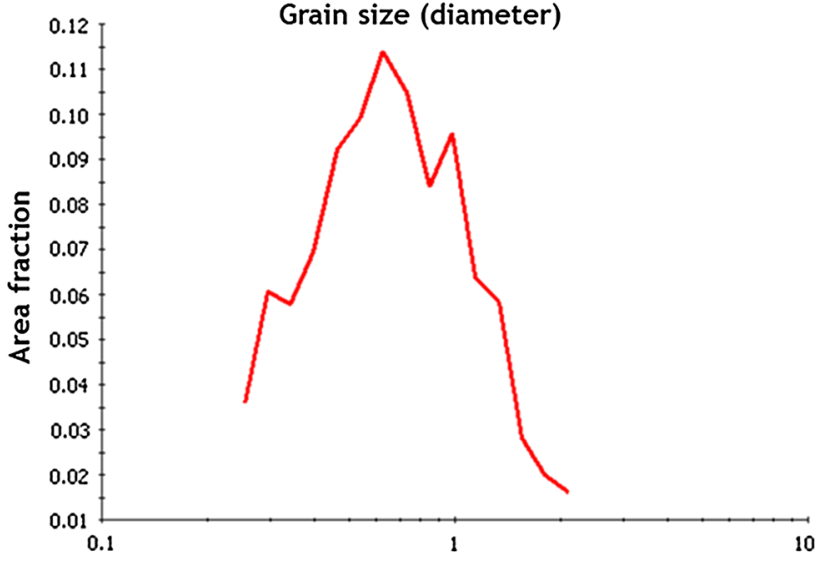

(a)

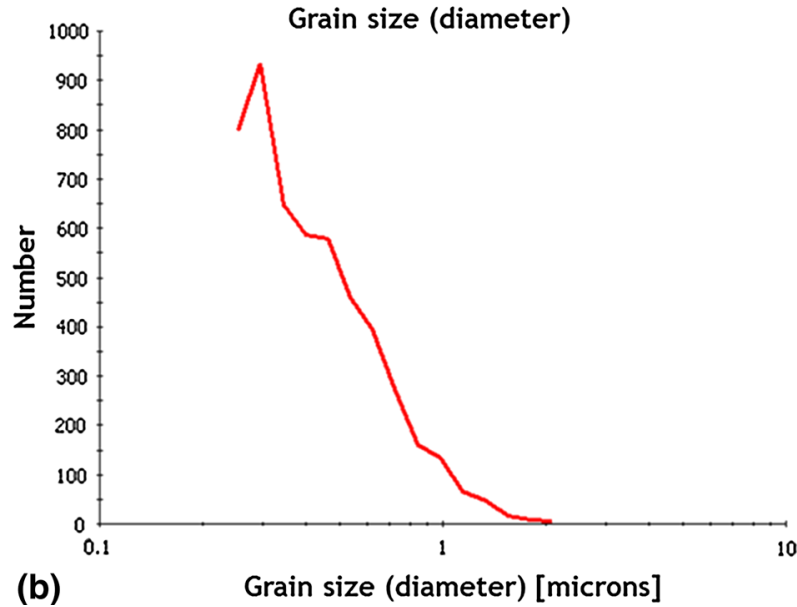

Fig. 9 The volume (a) and number (b) distribution of the grain size in ST52 coating microstructure

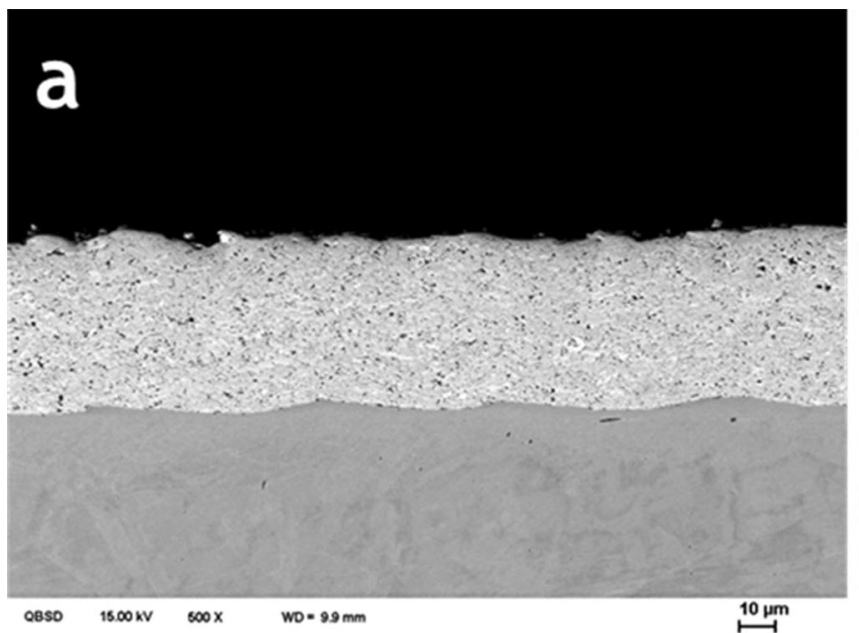

sample, enabled to find the main size of about $450 \mathrm{~nm}$, and the number distribution was less than $300 \mathrm{~nm}$ (see Fig. 12a and $b$ ).

The coating's surface was much smoother comparing to the coatings having columnar structure but also smoother with regard to other samples deposited using fine YSZ powder (Fig. 13). The single peaks on the surface profile could also be observed as a result of coarser particles that are present on coating surface. The SEM observations were confirmed by roughness measurements. The surface

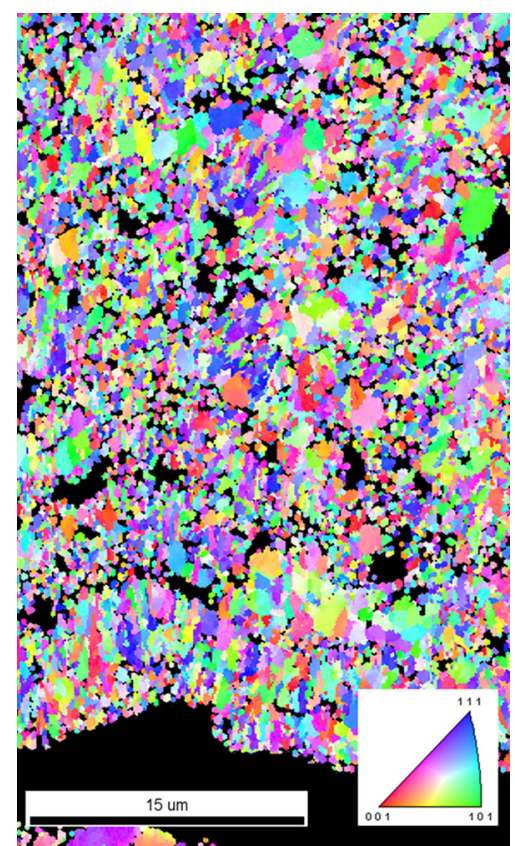

Fig. 11 EBSD map (inverse pole figure) of TC102 coating

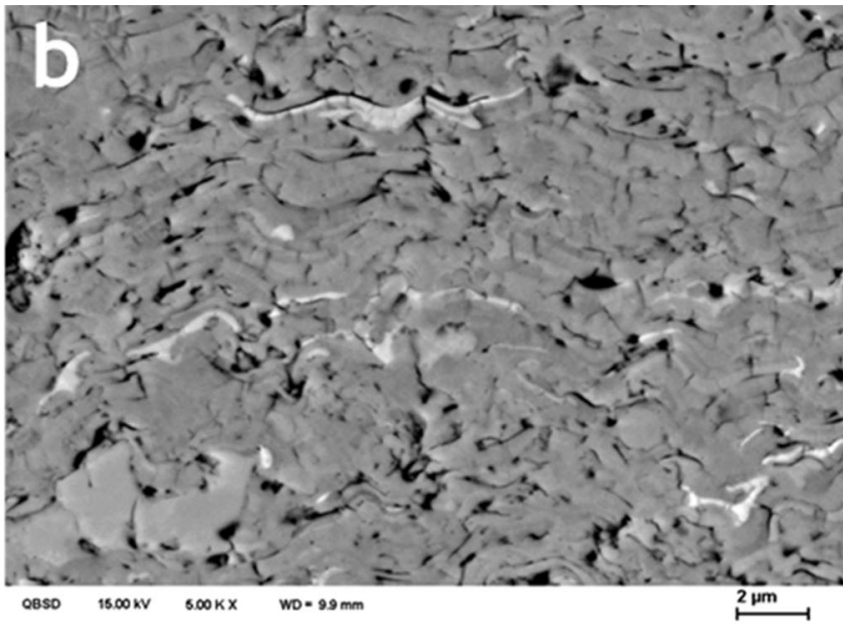

Fig. 10 SEM micrographs (backscattered electrons) of the TC102 sample with $500 \times$ (a) and $5000 \times$ magnification (b) 
of TC102 sample was characterized by $R_{\mathrm{a}}=3.2 \mu \mathrm{m}$ and $R_{\mathrm{z}}=23.2 \mu \mathrm{m}$. Furthermore, a decrease of roughness parameters with an increase in suspension concentration could be observed, especially for Triplex torch.
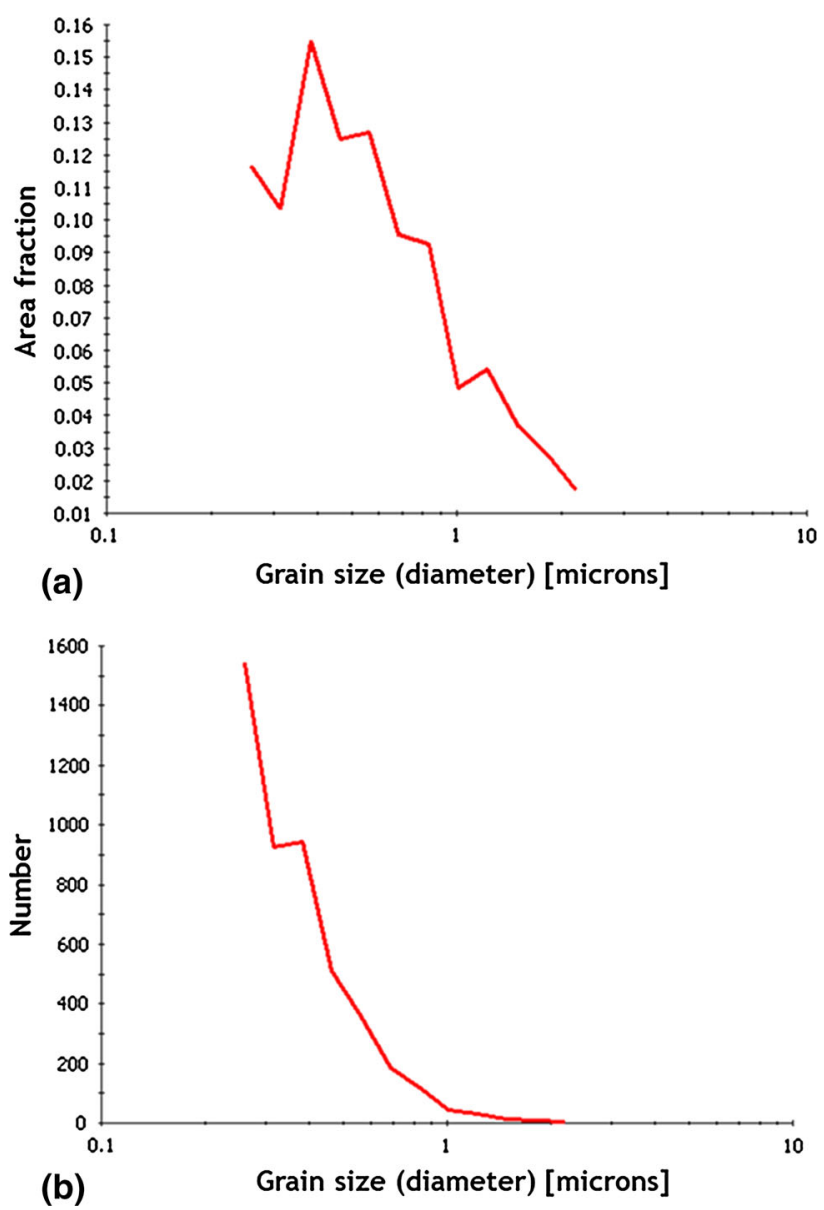

Fig. 12 The volume (a) and number (b) crystal grain size distribution of lamellar (TC102) sample

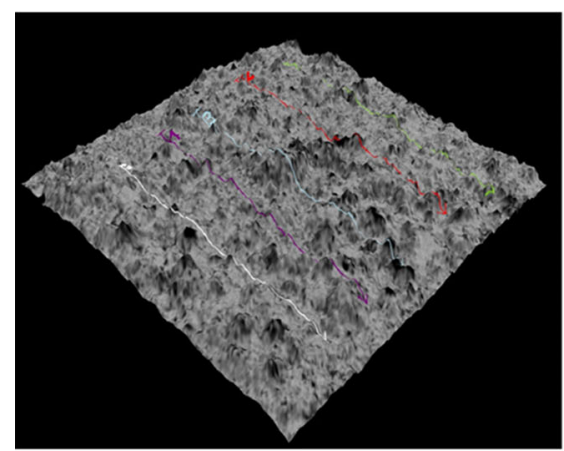

(a)

\section{Discussion}

The experiments were carried out in order to better understand the formation of the columnar and lamellar microstructures of suspension plasma-sprayed zirconia coatings but also to observe main differences between these microstructures. The coatings' growth mechanisms in SPS process were also investigated (Ref 14-16).

The coatings having columns were heterogeneous in terms of porosity, shape and size of grains, and the surface topography. Contrarily, the coatings with lamellas had fine-grained microstructure, regular distribution of micropores, and smooth surface.

These differences were caused by the hot gas fluctuations in contact with the substrate surface. The irregular columns could be created by the particles which followed the hot gas swirls and adhered mainly to the peaks of substrate or previous deposits forming columnar-like microstructure. The effect was strengthened by morphology of substrate surface and fine size of powder particles Fig. 14 (Ref 6, 7). The EBSD maps confirmed previous analyses and explanations. Another issue related to the behavior of powder particles that came into a contact with substrate resulted from equilibrium of forces (Ref 7, 17): (i) $F_{\mathrm{D}}$ - drag force pushing fine solids and (ii) adhesion force $F_{\mathrm{A}}$ keeping the particles on the substrate surface. Consequently, the particles could stick directly to the substrate or move parallel to it depending on which of these forces dominated. The relation $F_{\mathrm{A}}>F_{\mathrm{D}}$ is valid for larger particles transported close to the axis of plasma jet. But inside the coatings, the fractions of fine, unmelted, grains were noticed also. These zones were generated by particles that moved in external and colder regions of plasma. For these particles, the balance of forces changed and, consequently, $F_{\mathrm{D}}>F_{\mathrm{A}}$. Subsequently, they moved perpendicular to jet axis and adhered to an irregularity they meet on their way (Fig. 15). This mechanism connected with small amount of solid phase in the suspension, and low number of particles in the suspension droplet coming from the injector allows columns growing even when the substrate is smooth. This will be possible only if single irregularities ("roots") on the substrate surface will be created. Then the procedure will be similar as in the

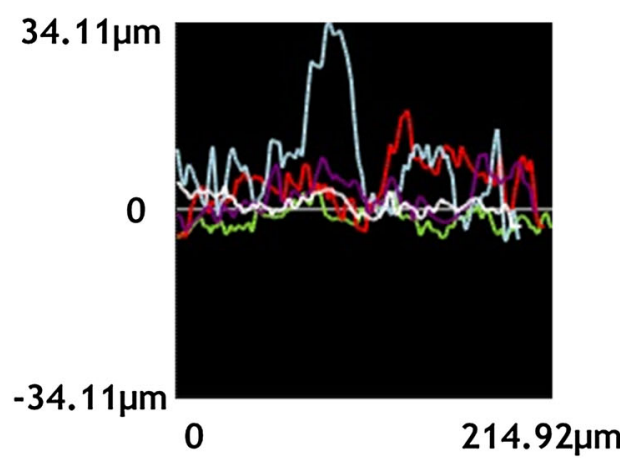

(b)

Fig. 13 Shape From Shading method applied to sample TC102: 3D view (a) and topography profile (b) 


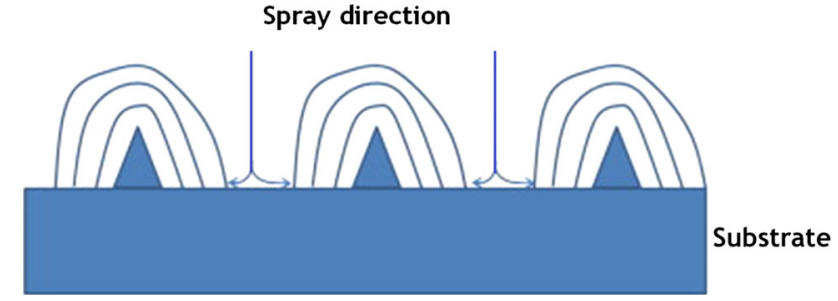

Fig. 14 Growth-up mechanism of columnar-like coatings through plasma fluctuations and shadowing effect (inspired by Ref 6,7)

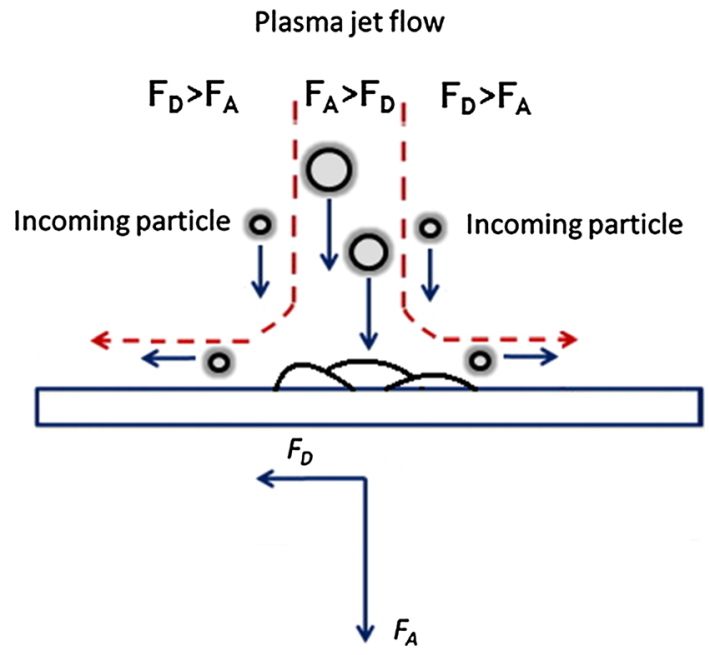

Fig. 15 The behavior of powder particles that come into a contact with substrate or previous deposits (inspired by Ref 7)

case of laser-treated substrate but as the result, much more irregular coatings will be formed (Fig. 16). Finally, the mechanism of columnar growth may be related to shadowing effect discussed elsewhere (Ref 6, 18). The growth of coating was rather an effect of intense accumulation of powder particles on surface peaks, than on its shadowed parts. This resulted in formation of columns or long, perpendicular to the substrate, pores, respectively (Fig. 14).

However, it should be stressed up that despite many attempts, it was not possible to achieve so regular columnar structure using SPS similar to that obtained with the physical vapor deposition (PVD) technology (Ref 19, $20)$. This can be explained by the fact that the particles used in SPS have a size many orders of magnitude greater than the atoms or molecules forming islands which become the columns during PVD processes.

The growth of lamellar microstructure resulted from suspension injection into the plasma and the phenomena occurring thereafter in the plasma jet Fig. 17 (Ref 5). This type of coating occurred mainly when the suspension had $10-20 \mathrm{wt} . \%$ of solid phase. As the injection systems in two plasma torches were different, there were some differences in morphologies of obtained coatings. The smaller

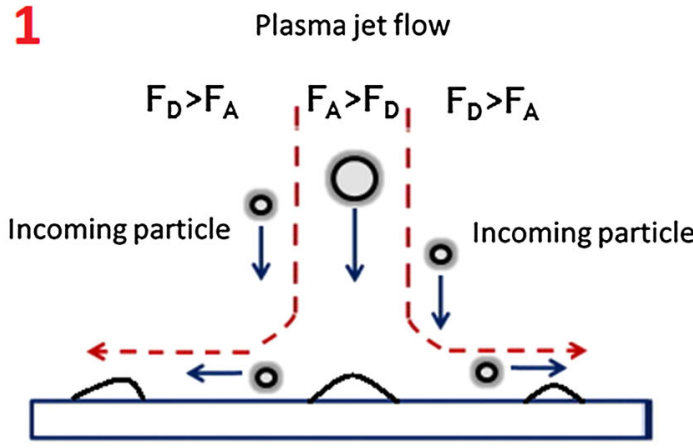

2

Plasma jet flow
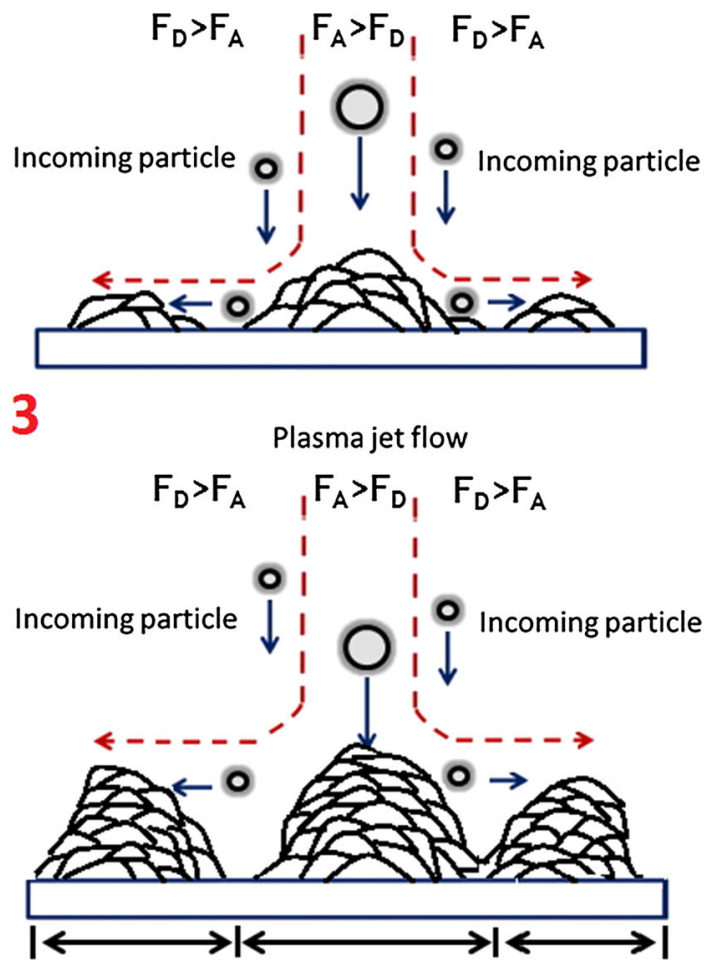

Fig. 16 The schematic illustration of columns formation on smooth surfaces for suspension containing low concentration of solid phase: 1 -irregularly distributed single splats create single "roots" for columns; 2 - particle trajectory depending on $F_{\mathrm{A}}$ and $F_{\mathrm{D}}\left(F_{\mathrm{D}}>F_{\mathrm{A}}\right.$ preferred because of particle size $)$; 3-continuous growth of columns supported by shadowing effect

and more concentrated droplets were injected into the plasma flux in Triplex setup, and as a result, more homogeneous coating was formed.

On the other hand, all mentioned coatings were formed using the same process-SPS-so among many differences, they showed also many similarities. Firstly, it was possible to observe, smaller or larger, completely randomly oriented lamellae and surrounding them micropores inside all columnar-like coatings. Furthermore, thin and longitudinal (columnar-like) grains inside big, flattened, lamella were observed, when analyzing coatings having lamellar microstructure like TC102. 


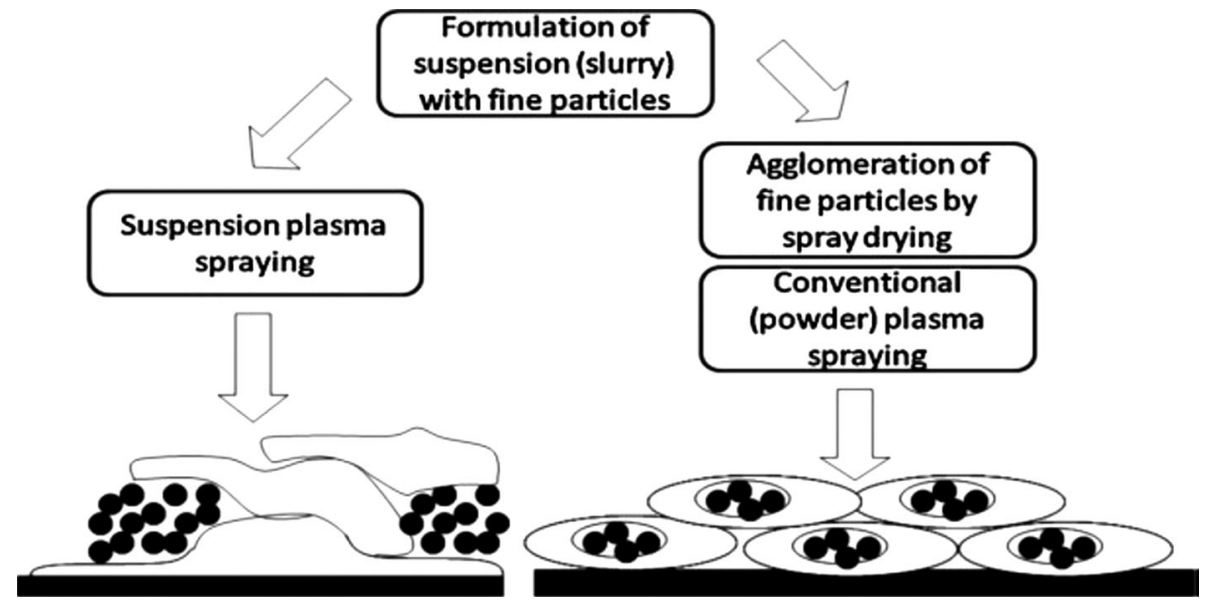

Fig. 17 The mechanism of formation conventional two-zone lamellar structure using Suspension Plasma Spraying method (Ref 5)

\section{Conclusions}

Advanced microstructural studies using scanning electron microscopy (SEM), energy dispersive $\mathrm{x}$-ray diffraction (EDS), electron beam scattering diffraction (EBSD), and finally $S F S$ method were used to characterize suspension plasma-sprayed zirconia coatings having different microstructures.

The research showed that the amount of solid phase used during suspension formulation had important influence on the microstructure of coatings, especially on porosity and topography of the coating surface. When using small amount, the porous and rough coatings were achieved. With the increase of solid phase amount, the porosity of coatings was decreasing. A similar effect was observed when the particles of powders with different size were used.

The differences in coating microstructure were observed also depending on which plasma torch was used during spray process. SG-100 of Praxair seemed to give more possibilities in producing coatings having different microstructures. At the same time, coatings deposited by Triplex of Oerlikon Metco were much more homogenous in term of porosity and coating topography.

The EDS analysis proved that the spray process did not influence the chemical composition of coatings. The concentration of the elements in coatings microstructure was close to that observed in initial powders.

The EBSD analysis proved that the suspension plasmasprayed coatings were composed of grains with random crystal orientation. The effect was related to the topography of the coatings as could be observed for coatings deposited on the laser-treated substrates. The analysis of the crystal grain size of coatings showed that their size is comparable or smaller than that of initial powders.

The $S F S$ technique was used to recreate and to analyze $3 \mathrm{D}$ views of coatings' topographies. The investigations showed that the suspension composition, powder particle size, and substrate preparation can be an important factor influencing coating topography. The roughness analysis was carried by non-contact laser confocal microscopy and proved correlations that were observed with the use of SFS method.

In future work, the studies of thermal and thermomechanical properties will be realized in order to verify what kind of coating microstructure is more beneficial for TBC's applications. For some applications, especially as thermal barrier coatings, the coatings having columnar microstructure seem to be more advantageous. The main benefit is high resistance for thermal shocks, which improves the sprayed coating in-service time (Ref 21). However, due to the fine-grained microstructure with the regular distributed micropores in the lamellar coating microstructure, the thermal transport is significantly reduced. The influence of the coatings microstructure on thermal conductivity was discussed previously (Ref 12,22 , 23). Therefore, the selection of adequate coatings microstructure for desired application has to be a compromise.

\section{Acknowledgments}

This research received support from the Grant Sonata, UMO-2013/11/D/ST8/03400, awarded to the Faculty of Mechanical Engineering at the Wroclaw University of Technology by the National Science Centre (Poland). French Embassy in Poland enabled the stay of Paweł Sokołowski at University of Limoges in frame of joint $\mathrm{PhD}$ "Co-tutelle" program which is realized in cooperation between France and Poland. The Polonium program attributed by the French Embassy in Poland helped in financing the visits of Polish researchers in France.

\section{Open Access}

This article is distributed under the terms of the Creative Commons Attribution 4.0 International License (http://creativecommons.org/licenses/by/4.0/), which permits unrestricted use, distribution, and reproduction in any medium, provided you give appropriate credit to the 
original author(s) and the source, provide a link to the Creative Commons license, and indicate if changes were made.

\section{References}

1. F. Gitzhofer, E. Bouyer, and M.I. Boulos, "Suspension Plasma Spraying”, US Patent 5,609,921, 3 Nov 1997

2. P. Fauchais, R. Etchart-Salas, V. Rat, J.F. Coudert, N. Caron, and K. Wittmann-Ténèze, Parameters Controlling Liquid Plasma Spraying: Solutions, Sols or Suspensions, J. Therm. Spray Technol., 2008, 17, p 31-59

3. R. Vaßen, H. Kaßner, G. Mauer et al., Suspension Plasma Spraying: Process Characteristics and Applications, J. Therm. Spray Technol., 2010, 19, p 219-225

4. S. Kozerski, L. Pawłowski, R. Jaworski, R. Francine, and F. Petit, Two Zones Microstructure of Suspension Plasma Sprayed Hydroxyapatite Coatings, Surf. Coat. Technol., 2010, 204, p 1380 1387

5. S. Kozerski, L. Łatka, L. Pawłowski, F. Cernuschi, F. Petit, C. Pierlot, H. Podlesak, and J.P. Laval, Preliminary Study on Suspension Plasma Sprayed $\mathrm{ZrO}_{2}+8$ wt. $\% \mathrm{Y}_{2} \mathrm{O}_{3}$ Coatings, J. Eur. Ceram. Soc., 2011, 31, p 2089-2098

6. K. VanEvery, M.J.M. Krane, R.W. Trice, H. Wang, W. Porter, M. Besser, D. Sordelet, J. Ilavsky, and J. Almer, Column Formation in Suspension Plasma-Sprayed Coatings and Resulting Thermal Properties, J. Therm. Spray Technol., 2011, 20(4), p 817-828

7. P. Sokołowski, S. Kozerski, L. Pawłowski, and A. Ambroziak, The Key Process Parameters Influencing Formation of Columnar Microstructure in Suspension Plasma Sprayed Zirconia Coatings, Surf. Coat. Technol., 2014, 260(15), p 97-106

8. R. Vaßen, H. Guo, and D. Stover, Manufacture and Properties of Segmented Thermal Barrier Coatings, Proceedings of the 29th International Cocoa Beach Conference \& Exposition, D. Zhu, W.M. Kriven, Ed., Jan 23-28, 2005 (Cocoa Beach, FL), Ceramic Engineering and Science Proceedings, Vol 26(38), p 37-45

9. N. Curry, K. VanEvery, T. Snyder, and N. Markocsan, Thermal Conductivity Analysis and Lifetime Testing of Suspension Plasma-Sprayed Thermal Barrier Coatings, Coatings, 2014, 4(3), p 630-650

10. E. Garcia, P. Miranzo, R. Soltani, and T.W. Coyle, Microstructure and Thermal Behavior of Thermal Barrier Coatings, J. Therm. Spray Technol., 2008, 17(4), p 478-485

11. B. Nait-Ali, K. Haberko, H. Vesteghem, J. Absi, and D.S. Smith, Thermal Conductivity of Highly Porous Zirconia, J. Eur. Ceram. Soc., 2006, 26(16), p 3567-3574

12. P. Sokołowski, L. Łatka, L. Pawłowski, A. Ambroziak, S. Kozerski, and B. Nait-Ali, Characterization of Microstructure and
Thermal Properties of YCSZ Coatings Obtained by Suspension Plasma Spraying, Surf. Coat. Technol., 2015, 268(25), p 147-152

13. B.K.P. Horn, "Shape from Shading: A Method for Obtaining the Shape of a Smooth Opaque Object from One View," Ph.D. thesis, Massachusetts Institute of Technology, 1970

14. H. Kassner, R. Siegert, D. Hathiramani, R. Vassen, and D. Stoever, Application of Suspension Plasma Spraying (SPS) for Manufacture of Ceramic Coatings, J. Therm. Spray Technol., 2008, 17(1), p 115-123

15. L. Łatka, S.B. Goryachev, S. Kozerski, L. Pawłowski, and T. Lampke, Buildup Mechanisms of Suspension Plasma Sprayed $\mathrm{ZrO}_{2}+8$ wt. $\% \mathrm{Y}_{2} \mathrm{O}_{3}$ Coatings, Thermal Spray 2011: Proceedings of the International Thermal Spray Conference and Exposition, Sept 27-29, 2011 (Hamburg, Germany), DVS Media, 2012, p. 104109

16. Z. Tang, H. Kim, I. Yaroslavski, G. Masindo, Z. Celler, and D. Ellsworth, Novel Thermal Barrier Coatings Produced by Axial Suspension Plasma Spray, Thermal Spray 2011: Proceedings of International Thermal Spray Conference and Exposition, Sept 27-29, 2011 (Hamburg, Germany), DVS Media, 2012, p 571-576

17. B. Pateyron, L. Pawłowski, N. Calve, G. Delluc, and A. Denoirjean, Modeling of phenomena occurring in plasma jet during suspension spraying of hydroxyapatite coatings, Surf. Coat. Technol., 2013, 214(15), p 86-90

18. G. Mauer, A. Hospach, N. Zotov, and R. Vaßen, Process conditions and microstructures of ceramic coatings by gas phase deposition based on plasma spraying, J. Therm. Spray Technol., 2013, 22(2-3), p 83-89

19. A. Guignard, Development of Thermal Spray Processes with Liquid Feedstocks, Forschungszentrum Jülich GmbH Zentralbibliothek, Verlag, Energie \& Umwelt/Energy \& Environment, Vol 141, 2012

20. U. Schulz, K. Fritscher, and M. Peters, EB-PVD $\mathrm{Y}_{2} \mathrm{O}_{3^{-}}$and $\mathrm{CeO}_{2} / \mathrm{Y}_{2} \mathrm{O}_{3}$-Stabilized Zirconia Thermal Barrier Coatings-Crystal Habit and Phase Composition, Surf. Coat. Technol., 1996, 82, p 259-269

21. W.A. Kaysser, M. Peters, K. Fritscher, and U. Schulz, Characterization and Testing of EB-PVD Thermal Barrier Coatings, AGARD Report 823, Thermal Barrier Coatings, NATO Neuillysur-Seine, Paris, AGARD, 1998

22. P. Carpio, Q. Blochet, B. Pateyron, L. Pawłowski, M.D. Salvador, A. Borrell, and E. Sanchez, Correlation of Thermal Conductivity of Suspension Plasma Sprayed Yttria Stabilized Zirconia Coatings with Some Microstructural Effects, Mater. Lett., 2013, 107, p 370-373

23. D.S. Smith, A. Alzina, J. Bourret, B. Nait-Ali, F. Pennec, N. Tessier-Doyen, K. Otsu, H. Matsubara, P. Elser, and U.T. Gonzenbach, Thermal Conductivity of Porous Materials, J. Mater. Res., 2013, 28(17), p 2260-2272 